\title{
Prevalence and long-term predictors of persistent chronic widespread pain in the general population in an 11-year prospective study: the HUNT study
}

Ingunn Mundal ${ }^{1,2^{*}}$, Rolf W Gråwe ${ }^{3 \dagger}$, Johan H Bjørngaard ${ }^{4,5 \dagger}$, Olav M Linaker ${ }^{1,6 \dagger}$ and Egil A Fors ${ }^{4,7 \dagger}$

\begin{abstract}
Background: Chronic widespread pain (CWP) is common and associated with prominent negative consequences. The aim of this study was to assess the prevalence of persistent CWP in an 11-year prospective cohort study in the general population, and to examine anxiety, depression, alcohol use, poor sleep, body mass index (BMI) and chronic disease, along with demographic, lifestyle and other health-related variables as possible predictors for the assumed CWP persistence.
\end{abstract}

Methods: CWP was defined as having pain at three or more predefined sites (involving the trunk and upper and lower limbs) for at least three months in the last year. We used a Norwegian general population cohort of 28,367 individuals who responded to both the second (1995-1997) and the third (2006-2008) waves of the Nord-Trøndelag Health Study (HUNT2 and HUNT3, respectively). Data were analysed with logistic regression models.

Results: CWP prevalence in HUNT2 was 17\%. Of those reporting CWP in HUNT2, 53\% still reported CWP at follow-up in HUNT3. Adjusted analyses revealed that depression and alcohol consumption were not substantially associated with the 11-year prospective CWP outcome. Poor sleep, obesity and chronic disease predicted persistent CWP, and being male and/or 60 years or older was protective.

Conclusions: This cohort study revealed that nearly half of the participants with baseline CWP resolved from CWP 11 years later. Among those whose CWP did not resolve, obesity, sleeping problems and chronic disease predicted CWP persistence, while aging and male sex was protective. Anxiety, mixed anxiety and depression, former smoking, and overweight were weakly associated, while depression, moderate exercise, and alcohol use were not associated with persistent CWP.

Keywords: Chronic widespread pain, Anxiety, Depression, Alcohol, Prospective cohort study, General population

\section{Background}

Chronic pain is common in the general population with a prevalence ranging from $20 \%$ to $55 \%$ [1-5]. Chronic pain persists beyond three months and is characterized by repeated or continuous pain episodes [6]. Other pain dimensions are quantitative (intensity) [7,8], qualitative

\footnotetext{
* Correspondence: ingunn.mundal@gmail.com

${ }^{\dagger}$ Equal contributors

${ }^{1}$ Department of Neuroscience, Faculty of Medicine, Norwegian University of Science and Technology, 7491 Trondheim, Norway

${ }^{2}$ Outpatient Department of Psychiatry, Kristiansund Hospital, Møre and Romsdal Hospital Trust, Kristiansund, Norway

Full list of author information is available at the end of the article
}

(burning, pressing pain) [9], and spatial measures (whether the pain is local, regional or widespread) [10-12]. Chronic widespread pain (CWP) is an important measure of the global burden of pain $[1,13]$, with a reported prevalence of $4 \%$ to $18 \%[14,15]$. These various aspects of chronic pain have been assessed extensively and studied together as one entity, but rarely separately. Wolfe et al. [16] have defined CWP as pain in the left and right sides of the body, above and below the waist, plus pain in the axial skeleton. CWP seems to be more prevalent in females than in males $[17,18]$, but it appears to be constant between age groups, and is associated with several complex medical conditions

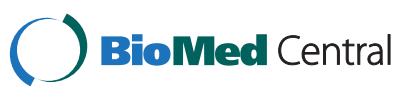


[19] and complaints, e.g. depression, anxiety, poor sleep, appetite disturbances and fatigue [20].

Cross-sectional studies have demonstrated that different pain characteristics are interrelated [21,22]. They have examined the relation between CWP prevalence, demographic variables, lifestyle factors, and self-reported health information $[21,23,24]$, and have also reported that multisite pain problems are significantly associated with mood and anxiety disorders, but not with alcohol abuse [25]. These factors are also assessed as risk factors of CWP onset in population-based prospective studies [15,26-28]. A recent review of risk factors associated with transitioning from regional pain to CWP suggested that females, those of older age, and those with a family history of pain and depressed mood, were all at higher risk [29].

A few population-based prospective studies have examined predictive factors of CWP persistence associated with CWP prevalence, suggesting that some $35 \%$ of those with initial CWP, are likely to experience persistence when they are females, of older ages, or exhibit additional physical or psychological symptoms [30,31]. In a three-year follow-up study of pain distribution and risk factors, Bergman and colleagues [32] found that the overall prevalence of CWP was persistent over a three-year period, where 57\% with initial CWP continued to have CWP at follow-up. While CWP persistence was predicted by the number of painful regions at baseline, as well by being an immigrant, having personal social support and drinking alcohol weekly seemed to be protective against persistence [32]. A 5.5 year prospective study of a Norwegian female population discovered that $61 \%$ with initial CWP continued to have CWP at follow-up [33]. Psychological symptoms were only assessed in one of these studies [30]. We are not aware of any large prospective population-based study investigating mood, chronic disease, lifestyle and demographic factors together as predictors of long-term CWP persistence. In view of the fact that CWP is closely associated with negative bio-psychosocial consequences [34] and mostly assessed in clinical samples, it is important to obtain knowledge of the overall impact of factors that predict CWP persistence in the general population.

The aim of this study was to 1) assess the prevalence, and 2) analyse possible predictive health-related, lifestyle and demographic factors as long-term predictive factors of CWP persistence. We hypothesized that (i) anxiety, depression, poor sleep, smoking and $\mathrm{BMI} \geq 25 \mathrm{~kg} / \mathrm{m}^{2}$ are predictors of CWP persistence and that (ii) young age, male sex, alcohol consumption and moderate exercise are protective factors.

\section{Methods}

\section{Study population and baseline}

This study is based on a large representative Norwegian cohort of individuals attending the second and third waves of the Nord-Trøndelag Health Study (HUNT2 and HUNT3, respectively). The HUNT study ("Helseundersøkelsen i Nord-Trøndelag”), designed as a longitudinal cohort study consisting of three health surveys, was carried out three times at 11 year intervals, in which all residents aged 20 years and older in Norway's Nord-Trøndelag County were invited to participate. The first survey (HUNT1) was conducted between 1984 and 1986, while HUNT2 and HUNT3 were performed in 1995-1997 and 2006-2008, respectively. HUNT1 was designed primarily to cover four sub-studies regarding hypertension, diabetes, lung diseases and quality of life [35], while the scientific programme in HUNT2 was extended to encompass large public health issues, including mental health and chronic musculoskeletal pain [36]. Pain data were not collected from HUNT1 and thus could not be included in this study. The health data in all the studies were collected in the same way, by interviews, self-administrated questionnaires and clinical examinations. The majority of participants in all HUNT surveys were middle aged or elderly (50 - 79 years) and female [35].

This study includes those 20 years and older in age (reaching 20 years during the year of screening in their municipality) who attended both HUNT2 and HUNT3 [35]. Of those invited in HUNT2, a total of 65,237 (70\%) participated. In HUNT3 a total of 93,860 were eligible for participation, where 50,807 (54\%) participated [36]. Participation in each survey was defined as having filled in questionnaire 1 (Q1), and a written consent form was delivered with Q1 when the participants attended the health examination sites. We included data collected from Q1, Q2 and the health examination (such as body mass index), and both questionnaires were distributed in HUNT2 and HUNT3. Whereas Q1 was a self-reporting questionnaire scored at home before attending the basic health examination, Q2 was handed out after the clinical examination and was to be completed at home and returned by mail [36].

Because the baseline questions related to pain were asked in Q1 in HUNT2 and the follow-up questions were asked in Q2 in HUNT3, it was necessary to include all subjects responding to both questionnaires in both surveys. Hence, 28,367 individuals - 16,260 (57\%) females and 12,107 (43\%) males - responded to Q1 and Q2 in both HUNT2 and HUNT3, and these individuals constituted the study population. Of these, 4,927 participants reported CWP in HUNT2 and thus provided the baseline sample (see Figure 1).

\section{Dependent variable - CWP as reported in HUNT3}

The chronicity of musculoskeletal pain was determined by the participants responding positively with a "yes" on the following question from the validated Standardized Nordic Questionnaire (SNQ): "During the last year, have you had pain and/or stiffness in your muscles and limbs 


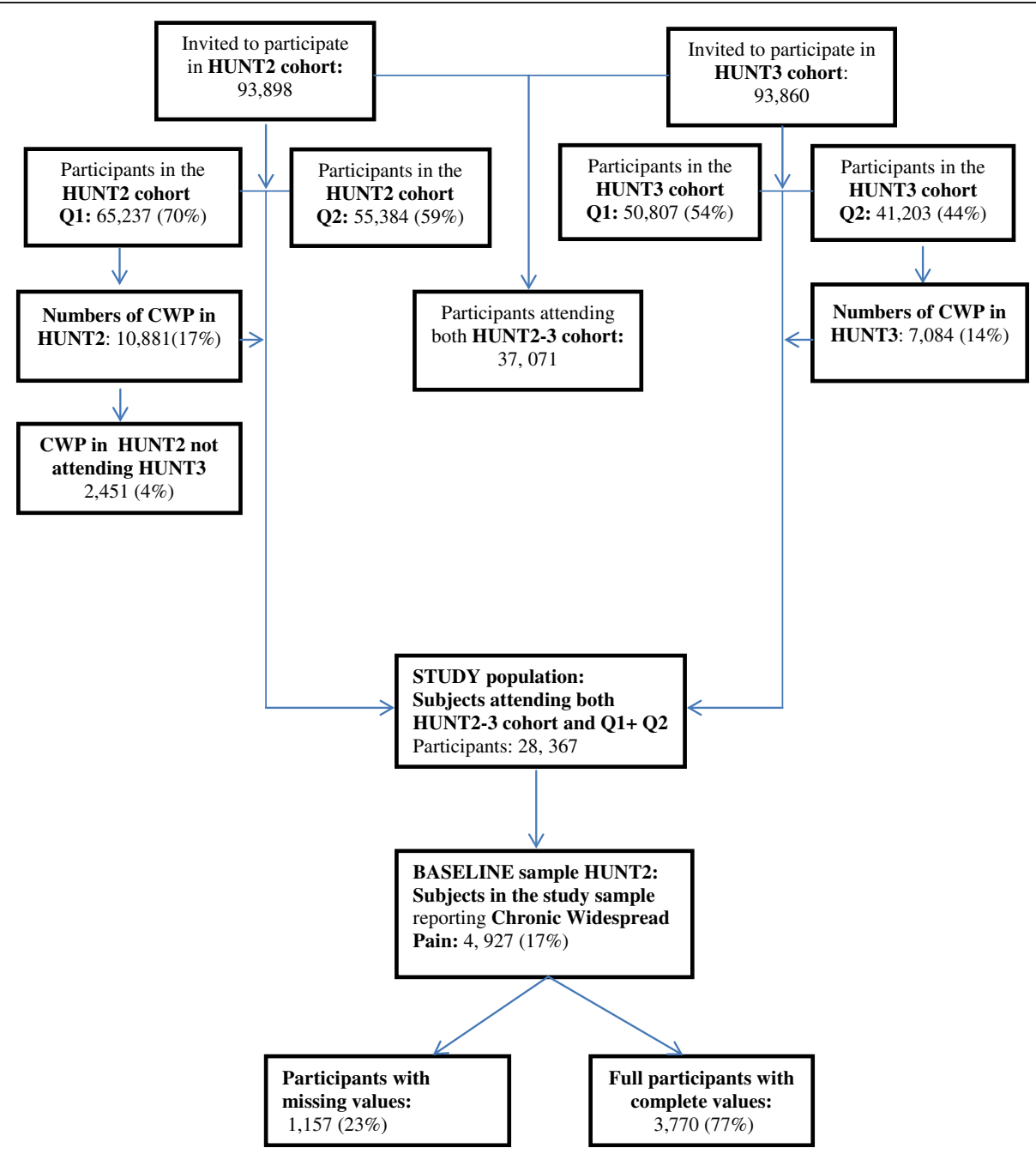

Figure 1 Flowchart showing the inclusion of participants in the HUNT2 and HUNT3 study (Q1), the study population (participants responding to both Q1 and Q2 in HUNT2 and HUNT3) and baseline sample (chronic widespread pain in HUNT2) calculated from the study population. Q1: Questionnaire 1, Q1: Questionnaire 2.

that has lasted for at least 3 consecutive months?" [37]. Those reporting chronic pain were invited to specify their pain location(s) on a map of the human outer body [38]. The location included the following nine possible pain sites: neck, shoulder, elbow, hand/wrist, upper back, lower back, hip, knee and ankle/foot. If the participants responded "yes" to the introductory question but did not respond to the follow-up location question, they were still considered as having chronic pain, albeit not in the pictured area. The outcome variable CWP was constructed according to the Standardized Nordic Questionnaire and the American College of Rheumatology's (ACR) defined criteria for CWP [39]. CWP in the present study was defined as having chronic pain in all the following three major body areas: the trunk (i.e. at least one of the following locations: neck, lower back, and/or upper back), lower limbs (i.e. at least one of the following: ankles, feet, knees and/or hips), and upper limbs (i.e. at least one of the following: shoulders, elbows and/or hands). As in the original version of SNQ, the subjects in HUNT3 could indicate bilateral bodily pain, but this information was omitted because of the lack of ability to indicate bilateral pain in HUNT2, where the baseline CWP variable was computed. According to ACR's abbreviated definition, widespread pain is described as axial pain, left- and rightside pain, and upper- and lower-segment pain [39]. Pain in the left or right shoulder and buttock was considered as pain in each side, and lower-back pain was considered as lower-segment pain [16]. Thus, CWP was defined as the presence of pain in all four quadrants of the body. We analysed the CWP as a categorical variable, with categories 0 and 1 . 


\section{Possible predictors}

The independent variables were sex and baseline information on age, separate anxiety and depression measures from the Hospital Anxiety and Depression Scale (HADS), alcohol use, insomnia and body mass index (BMI). Variables also included smoking status, marital status, education, exercise, and chronic disease, all of which were observed in the HUNT2 period. HADS is a well-established and validated 14-item, self-rating questionnaire that aims to detect general symptoms of anxiety and depression. It comprises seven items for depression (HADS-D) and seven for anxiety (HADS-A), in which each item includes a four-point Likert-scale response category (0-3) [40,41]. A mixed HADS variable was constructed and categorized into four groups: neither anxiety nor depression, pure depression, pure anxiety, and both depression and anxiety. The cut-off score of $\geq 8$ was set to define the caseness of having anxiety or depression, and a cut-off score of $\geq 8$ on each indicated the caseness of having both anxiety and depression $[40,42]$. In this study we wanted to examine the concurrence of anxiety and/or depression symptoms in relation to the scope of musculoskeletal pain rather than identifying the actual caseness of having anxiety and/or depression. However, the cut-offs were set to mark the borderline of depression or anxiety or both, even though a structured clinical interview, e.g. SCID-I, is the golden standard in clinical settings [43]. Because data from alcohol screening tools could not adequate reflect problems with alcohol, we decided to use data related to the frequency of alcohol use. The frequency of alcohol consumption was identified by two questions: "Concerning alcohol, are you a non-drinker?" and "how many times a month do you normally drink alcohol?" Responses were categorized as 1) abstainer, 2) drinking 0 times a month, 3) drinking 1-7 times a month, or 4) drinking 8 times or more a month. Drinking alcohol 0 times a month indicates a person that rarely drinks alcohol, but is not the same as a non-drinker by principle.

The influences that sleeping problems had on the CWP outcome were examined by using three questions from Q2, each related to non-restorative sleep, difficulties of sleep onset, and problems of maintaining sleep. Non-restorative sleep was identified by asking "how often do you suffer from insomnia?", where the response options included "never or a few times a year", "1-2 times a month", "about once a week" and "more than once a week". Problems of sleep onset and maintaining sleep were measured by two questions: "Have you had difficulty falling asleep in the last month?" and "during the last month, have you woken too early and not been able to get back to sleep?" Response options included "almost every night", "often", "now and again" and "never", where the responses "almost every night" and "often" were defined as problems (1) and "now and again" and "never" as no problems (0). The three variables of "non-restorative sleep", "sleep onset" and "maintaining sleep" were combined into one variable reflecting sleeping problems and categorized as "no problem" or "problem" (i.e. reporting 1 or more sleeping problems on the 3 items). According to the cut-offs recommended from the World Health Organization's Global Database on Body Mass Index, [44], BMI was computed from the height and weight measurements and categorized into four groups as: underweight $\left(\mathrm{BMI}<18.5 \mathrm{~kg} / \mathrm{m}^{2}\right)$, normal (BMI $\left.18.5-24.9 \mathrm{~kg} / \mathrm{m}^{2}\right)$, overweight (BMI $25-29.9 \mathrm{~kg} / \mathrm{m}^{2}$ ) and obese (BMI $\left.\geq 30 \mathrm{~kg} / \mathrm{m}^{2}\right)$. Smoking was identified by using a constructed variable of smoking status categorized into "never smoking", "previous smoking" and "current smoking". Data on marital status and age were provided from the National Population Registry. Marital status was categorized into two groups: "single/divorced/separated/widower" and "married/cohabitant/partnership". Education level was specified in three categories: "primary school", "high-school" and "university/ college of four years or more". Physical exercise was measured through two variables of light and hard duration as: "average of hours of both light and hard physical activity per week in the last year" and reflected "no" up to "moderate" levels of physical activity. Long-term illness (chronic disease) was evaluated by the question "do you suffer from any long-term illness or injury of a physical or psychological nature that impairs your functioning in everyday life?" where "long term" means at least one year. The response options were "yes/no". The "no pain" group in the study population covered all subjects that did not satisfy the CWP criteria, including those that responded "yes" to the introductory question on pain but did not indicate the site of pain. The sex ratios were calculated by dividing female prevalence by male prevalence.

\section{Statistical analysis}

Two models were used to examine predictors of CWP persistence. The examination of each was performed through logistic regression analyses resulting in odds ratios, with 95\% confidence intervals. Model 1 captured the results from each variable of interest in a crude age- and sexadjusted analysis. In model 2, all variables were included in one multivariable model. Because some variables were missing observations, only complete cases were included in the regression analyses. Missing observations concerned 1,157 respondents (23\%) from the baseline sample. The analyses were examined for statistical interactions between sex and the independent variables. All data were analysed by using Stata 12.1 for Windows (Stata Corporation, USA).

\section{Ethics}

This study was approved by the Board of Research Ethics in Health Region IV of Norway and the National Data Inspectorate. 


\section{Results}

Of the 28,367 subjects who completed the introductory question on chronic musculoskeletal pain, 28,313 subjects were included in HUNT2 and 27,574 were included in HUNT3. The overall mean age in the HUNT2 cohort was 50.1 years (SD 17.2), ranging from 19.1 to 101.1 years, while the mean age in the HUNT3 cohort was 53.1 years (SD 16.1), ranging from 19.0 to 100.8 years (data not shown). The mean age in the baseline sample (CWP in HUNT2) was 52.3 years (SD 11.4), varying between 19.5 to 85.9 years. The age distribution frequency of the baseline sample showed that the majority of the participants (59\%) were aged 40 to 59 years. The mean baseline HADS depression and anxiety scores were 4.42 (SD 3.32) and 5.50 (SD 3.7), respectively, versus 3.49 (SD 3.1) and 4.24 (SD 3.4), respectively, in the study population (data not shown). Descriptive data on the variables of interest are described in Table 1.

The mean HADS scores in the HUNT2 study population were similar to the mean HADS scores in the HUNT2 cohort. Only $0.4 \%$ of the study population reported chronic musculoskeletal pain without specifying any pain location.

\section{Prevalence of persistent chronic widespread pain after 11 years}

Of those reporting CWP in HUNT2 (i.e. baseline $=17 \%$ ), $53 \%(\mathrm{n}=1,997)$ still reported CWP in the HUNT3 followup, and $74 \%$ of these were females. By comparison, the overall female proportion in the study population was $57 \%$.

\section{Regression results Crude analysis}

From the health-related variables in the unadjusted analysis (see Table 2), symptoms of depression (OR: 1.28, 95\% confidence interval (CI): 0.96-1.69) indicated a weak increase in CWP persistence. Symptoms of anxiety showed a 35\% increased odds of CWP (OR: 1.35, 95\% CI: 1.121.62), while symptoms of mixed anxiety and depression showed a $48 \%$ increased odds of CWP persistence (OR: 1.46, 95\% CI: 1.19-1.82), versus the absence of anxiety and depression symptoms. Similarly, sleeping problems showed an increased CWP persistence compared with no sleeping problems (OR: 1.49, 95\% CI: 1.30-1.71). Those with a chronic disease had almost twice the odds of CWP persistence compared to those without a chronic disease (OR: 1.89, 95\% CI: 1.66-2.16).

Compared with never smokers, former smokers were at greater risk of CWP persistence (OR: 1.23, 95\% CI: 1.051.45), while current smokers differed only marginally from never smokers (OR: 1.14, 95\% CI: 0.97-1.33). Compared with study participants with normal weight, obese participants had higher odds of CWP persistence (OR: 1.68, 95\%
CI: 1.39-2.02). Drinking alcohol 8 times or more a month (OR: 0.85, 95\% CI: 0.60-1.21) showed a non-substantial protective tendency when compared with abstainers. Participants 60 years or older had a lower odds of CWP persistence (OR: 0.76, 95\% CI: 0.62-0.93) compared with the youngest age group (age 20-39). Also, those with an education at the university/college level had a lower odds of CWP persistence (OR: 0.76, 95\% CI: 0.62-0.93) than those with a primary education only. Males had about half the odds of CWP persistence (OR: 0.53, 95\% CI: 0.460.61) compared with females.

\section{Adjusted analysis}

In the adjusted analysis, symptoms of anxiety (OR: 1.24, 95\% CI: 1.02-1.50) and mixed anxiety and depression (OR: 1.18, 95\% CI: $0.95-1.47)$ only indicated a weak increase in CWP persistence. Sleeping problems remained a substantial predictor of CWP persistence (OR: 1.30, 95\% CI: $1.12-$ $1.51)$, compared with the lack of sleeping problems. Those with a chronic disease had a $75 \%$ increased odds of CWP persistence (OR: 1.75. 95\% CI: 1.53-2.01) compared with participants without a chronic disease. Adjusted for the other possible predictors, overweight participants had a weak increased odds of CWP persistence (OR: 1.18, 95\% CI: 1.01-1.32) while obese participants had a $66 \%$ increased odds of CWP persistence (OR: 1.66, 95\% CI: 1.372.01) compared with normal weight individuals. Former smokers had a weak increase in CWP persistence (OR: 1.18, 95\% CI: 1.00-1.39) compared with never smokers. Compared with the youngest age group (age 20-39), study participants 60 years or older showed a reduced odds of CWP persistence (OR: 0.63, 95\% CI: 0.50-0.81), and males had about half the odds of CWP persistence (OR: 0.51, 95\% CI: 0.44-0.59) compared to females. All results, both crude and adjusted models, are presented in Table 2.

\section{Comparison of HUNT3 non-participants and participants with CWP in HUNT2}

Some participants experienced CWP in HUNT2, but did not attend HUNT3 $(\mathrm{n}=2,451)$. To obtain descriptive measures, these HUNT3 non-participants were compared to the HUNT3 participants who had CWP in HUNT2, i.e. the baseline sample $(n=4,927)$. The mean age of nonparticipants was 54.4 years (SD 15.7). Compared to the baseline sample, non-participants were more likely to be obese, have sleeping problems and smoke daily. There were also group differences in age distribution, education, marital status and chronic disease. The results are presented in Table 3.

\section{Statistical interaction analyses}

Statistical interaction analyses indicated weak evidence of statistical interaction between sex and the other evaluated variables $(\mathrm{p}>0.12)$. 
Table 1 Sample characteristics of the study population and baseline sample (Widespread pain in HUNT2)

\begin{tabular}{|c|c|c|c|c|}
\hline & $\begin{array}{l}\text { Study population } \\
\mathrm{N}=28,367(\%) \S\end{array}$ & $\begin{array}{l}\text { *Baseline sample } \\
\mathrm{N}=4,927(\%) \S\end{array}$ & $\begin{array}{l}\text { Female } \\
\mathrm{N}=3,372(68.4)\end{array}$ & $\begin{array}{l}\text { Male } \\
\mathrm{N}=1,555 \text { (31.6) }\end{array}$ \\
\hline Sex Females (\%) & $16,260(57)$ & & & \\
\hline Males (\%) & $12,107(43)$ & & & \\
\hline Age in years, mean (SD) & $47.6(13.3)$ & $52.3(11.4)$ & $51.7(11.5)$ & $53.7(11.1)$ \\
\hline 20-39, (\%) & $8,397(30)$ & $733(15)$ & $558(17)$ & $175(11)$ \\
\hline $40-59$ & $24,664(50)$ & 2,892 (59) & $1,996(59)$ & $896(58)$ \\
\hline 60 years or older & $5,707(20)$ & $1,302(26)$ & $818(24)$ & $484(31)$ \\
\hline \multicolumn{5}{|l|}{ HADS score; (\%) } \\
\hline HADS, (\%) score < 8, & $22,560(81)$ & $3,209(67)$ & $2,130(65)$ & $1,079(71)$ \\
\hline HADS-D, cut off score $\geq 8$, & $1,124(4)$ & $300(6)$ & $167(5)$ & $133(9)$ \\
\hline HADS-A, cut off score $\geq 8$, & $2,672(10)$ & $754(16)$ & $583(18)$ & $171(11)$ \\
\hline HADS-mixed & $1,451(5)$ & $530(11)$ & $389(12)$ & $141(9)$ \\
\hline \multicolumn{5}{|l|}{ Sleeping difficulties (\%) } \\
\hline No problems & $21,597(81)$ & $2,929(63)$ & $1,899(59)$ & $1,030(70)$ \\
\hline Problems & $5,195(19)$ & $1,751(37)$ & $1,319(41)$ & $432(30)$ \\
\hline Alcohol use - abstainers (\%) & $2,546(9)$ & $552(12)$ & $444(14)$ & $108(7)$ \\
\hline 0 times/month & $7,256(27)$ & $1,516(32)$ & $1,156(36)$ & $360(24)$ \\
\hline 1-7 times/month & $15,790(58)$ & $2,398(51)$ & $1,488(46)$ & $910(61)$ \\
\hline $8 \geq$ times/month & $1,718(6)$ & $240(5)$ & $123(4)$ & $117(8)$ \\
\hline \multicolumn{5}{|l|}{ BMI (\%) } \\
\hline Underweight & $150(1)$ & $23(1)$ & $20(1)$ & $3(0.2)$ \\
\hline Normal & $11,378(40)$ & $1,593(32)$ & $1,189(35)$ & $404(26)$ \\
\hline Overweight & $12,606(45)$ & $2,262(46)$ & $1,394(41)$ & $868(56)$ \\
\hline Obesity & $6,984(25)$ & $1,040(21)$ & $761(23)$ & 279 (18) \\
\hline \multicolumn{5}{|l|}{ Smoking status, (\%) } \\
\hline Never smoked & $12,912(46)$ & $1,759(36)$ & $1,315(39)$ & $444(29)$ \\
\hline Former smoker & $8,249(29)$ & $1,612(33)$ & $940(29)$ & $672(44)$ \\
\hline Current smoker & $6,984(25)$ & $1,517(31)$ & $1,089(28.2)$ & $428(28)$ \\
\hline \multicolumn{5}{|l|}{ Exercise, moderate $(\%)$} \\
\hline No exercise & $16,123(60)$ & $2,974(65)$ & $2,044(66)$ & $932(63)$ \\
\hline Moderate exercise & $10,731(40)$ & $1,575(35)$ & $1,035(34)$ & $540(37)$ \\
\hline \multicolumn{5}{|l|}{ Education in years (\%) } \\
\hline Primary school (\%) & $8,678(31)$ & 2,129 (45.6) & $1,562(48)$ & $617(41)$ \\
\hline High school & $12,649(46)$ & $1,946(40.7)$ & $1,229(38)$ & $717(47)$ \\
\hline College & $6,435(23)$ & $653(13.7)$ & $472(14)$ & $181(12)$ \\
\hline \multicolumn{5}{|l|}{ Marital status (\%) } \\
\hline Not married/cohabitant & $8,620(30)$ & $1,226(25)$ & $882(26)$ & $344(22.2)$ \\
\hline Married/cohabitant & $19,694(70)$ & $3,690(75)$ & $2,482(74)$ & $1,208(78)$ \\
\hline \multicolumn{5}{|l|}{ Chronic disease, (\%) } \\
\hline No & $21,018(77)$ & $2,156(47)$ & $1,527(49)$ & $629(42)$ \\
\hline Yes & $6,116(23)$ & $2,418(53)$ & $1,566(51)$ & $852(58)$ \\
\hline
\end{tabular}

§N in Study population will vary due to missing data.

*Calculated from the study population $\mathrm{N}=28,367$ (respondents of BOTH questionnaires Q1 and Q2 in HUNT2 and HUNT3).

$\mathrm{N}$ will vary slightly because of missing data. 
Table 2 Odds ratios (ORs) with $95 \%$ confidence intervals (Cls) for persistent chronic widespread pain in HUNT3

\begin{tabular}{|c|c|c|c|c|}
\hline Baseline variables HUNT2 & $\begin{array}{l}N=3,770 \\
N(\%)\end{array}$ & CWP in HUNT3 $N=1,997$ & $\begin{array}{l}\text { Model } 1 \text { - crude model } \\
\text { OR }[95 \% \mathrm{Cl}]\end{array}$ & $\begin{array}{l}\text { Model } 2 \text { - adjusted model } \\
\text { OR }[95 \% \mathrm{Cl}]\end{array}$ \\
\hline Sex Female [ref.] & $2,540(67)$ & $1,447(74)$ & 1.00 & 1.00 \\
\hline Male & $1,230(33)$ & $520(26)$ & $0.53[0.46-0.61]$ & $0.51[0.44-0.59]$ \\
\hline Age, 20-39 yrs [ref.] & $643(17)$ & $342(17)$ & 1.00 & 1.00 \\
\hline Age, 40-59 yrs (<40 yrs [ref.]) & $2,388(63)$ & $1,323(66)$ & $1.12[0.94-1.34]$ & $1.03[0.85-1.25]$ \\
\hline$\geq 60 \mathrm{yrs}$ & $739(20)$ & $332(17)$ & $0.76[0.62-0.94]$ & $0.63[0.50-0.81]$ \\
\hline HADS (A/D <8 [ref.]) & $2,544(67)$ & $1,276(64)$ & 1.00 & 1.00 \\
\hline HADS Depression (D) $\geq 8$ & $220(6)$ & $120(6)$ & $1.28[0.96-1.69]$ & $1.12[0.84-1.50]$ \\
\hline Anxiety $(A) \geq 8$ & $578(15)$ & $343(17)$ & $1.35[1.12-1.62]$ & $1.24[1.02-1.50]$ \\
\hline Depression $\geq 8$ AND Anxiety $\geq 8$ & $428(11)$ & $260(13)$ & $1.48[1.19-1.82]$ & $1.18[0.95-1.47]$ \\
\hline Sleep problems, never [ref.] & $2,544(64)$ & $1,195(60)$ & 1.00 & 1.00 \\
\hline Often & $1,345(36)$ & $802(40)$ & $1.49[1.30-1.71]$ & $1.30[1.12-1.51]$ \\
\hline Smoke status, never smoking [ref.] & $1,315(35)$ & $667(33)$ & 1.00 & 1.00 \\
\hline Ex. smoker & $1,235(33)$ & $665(33)$ & $1.23[1.05-1.45]$ & $1.18[1.00-1.39]$ \\
\hline Current daily smoker & $1,220(32)$ & $665(33)$ & 1.14 [0.97-1.33] & $1.10[0.93-1.31]$ \\
\hline BMI normal $18.5-24.9$ kg/m² [ref.] & $1,262(33)$ & $633(32)$ & 1.00 & 1.00 \\
\hline Underweight $<18.5 \mathrm{~kg} / \mathrm{m}^{2}$ & $21(0.6)$ & $7(0.35)$ & $0.46[0.18-1.15]$ & $0.43[0.17-1.10]$ \\
\hline Overweight $25-29.9 \mathrm{~kg} / \mathrm{m}^{2}$ & $1,730(46)$ & $893(45)$ & $1.17[1.01-1.36]$ & 1.18 [1.01-1.37] \\
\hline Obese $\geq 30 \mathrm{~kg} / \mathrm{m}^{2}$ & $757(20)$ & $464(23)$ & $1.68[1.39-2.02]$ & $1.66[1.37-2.01]$ \\
\hline Alcohol-monthly use, abstainers [ref.] & $375(10)$ & $205(10)$ & 1.00 & 1.00 \\
\hline 0 time a month & $1,139(30)$ & $615(31)$ & $0.94[0.74-1.20]$ & $0.97[0.76-1.24]$ \\
\hline 1-7 times a month & $2,046(54)$ & $1,077(54)$ & $0.95[0.76-1.19]$ & $1.01[0.79-1.28]$ \\
\hline 8 times or more a month & $210(6)$ & $100(5)$ & $0.85[0.60-1.21]$ & $0.90[0.62-1.29]$ \\
\hline Education, primary school, [ref.] & $1,546(41)$ & $824(41)$ & 1.00 & 1.00 \\
\hline High school & $1,661(44)$ & $900(45)$ & $1.03[0.89-1.20]$ & $1.10[0.94-1.28]$ \\
\hline University/college & $563(15)$ & $273(14)$ & $0.76[0.62-0.93]$ & $0.86[0.70-1.06]$ \\
\hline Exercise, low/no [ref.] & $2,487(66)$ & $1,338(67)$ & 1.00 & 1.00 \\
\hline Moderate & $1,283(34)$ & $659(33)$ & $0.94[0.82-1.07]$ & $0.97[0.84-1.12]$ \\
\hline Marital status - single [ref.] & $925(25)$ & $505(25)$ & 1.00 & 1.00 \\
\hline Married & $2,845(75)$ & $1,492(75)$ & $0.92[0.79-1.07]$ & $0.94[0.80-1.10]$ \\
\hline Disease Chronic, no [ref.] & $1,806(48)$ & $830(42)$ & 1.00 & 1.00 \\
\hline Yes & $1,964(52)$ & $1,167(58)$ & $1.89[1.66-2.16]$ & $1.75[1.53-2.01]$ \\
\hline
\end{tabular}

Model 1: Crude - age and sex adjusted.

Model 2: All variables included.

Only complete cases included.

\section{Discussion}

In this large prospective cohort study, $53 \%$ of the participants with baseline CWP still had CWP at follow-up. According to the adjusted model, we found strong positive associations over time between persistent CWP and sleeping problems, being obese and having a chronic disease, while anxiety, mixed anxiety and depression symptoms, former smoking and being overweight showed weaker positive associations with persistent CWP 11 years later. Being a male and being 60 years of age were substantial protective factors against long-term persistent CWP.

\section{Strengths and weaknesses \\ Strengths}

A major strength of this study was its large population base, its acceptable participation rate and its long-term follow-up. The study also contained a robust design and a lot of variables for comparing between different follow-up times. The pain measures were gauged with validated, well-known and standardized questionnaires that rely on self-reporting [1], which also would allow for reliable comparisons. By allowing the respondents to select individual body pain sites, we obtained a picture of the extent and 
Table 3 Comparison of measures of non-participants ${ }^{a}$ in HUNT3 with CWP in HUNT2, and the baseline sample ${ }^{b}$

\begin{tabular}{|c|c|c|}
\hline & $\begin{array}{l}{ }^{\text {aNon-participants }} \\
\text { HUNT3 } \\
\mathrm{N}=2,451(\%) \S\end{array}$ & $\begin{array}{l}\text { bBaseline sample } \\
\text { HUNT2 } \\
\mathrm{N}=4,927 \text { (\%)§ }\end{array}$ \\
\hline Sex Females (\%) & $1,634(67)$ & $3,372(68)$ \\
\hline Males (\%) & $817(33)$ & $1,555(32)$ \\
\hline Age in years, mean (SD) & $54.4(15.7)$ & $52.3(11.4)$ \\
\hline 20-39, (\%) & $513(21)$ & $733(15)$ \\
\hline $40-59$ & $964(39)$ & $2,892(59)$ \\
\hline 60 years or older & $974(40)$ & $1,302(26)$ \\
\hline \multicolumn{3}{|l|}{ HADS score; (\%) } \\
\hline HADS, (\%) score < 8 & $1,426(63)$ & $3,209(67)$ \\
\hline HADS-D, cut off score $\geq 8$ & $141(6)$ & $300(6)$ \\
\hline HADS-A, cut off score $\geq 8$ & $374(16)$ & $754(16)$ \\
\hline HADS-mixed & $327(14)$ & $530(11)$ \\
\hline \multicolumn{3}{|l|}{ Sleeping difficulties (\%) } \\
\hline No problems & $834(53)$ & $2,929(63)$ \\
\hline Problems & $759(47)$ & $1,751(37)$ \\
\hline Alcohol use - abstainers (\%) & $396(17)$ & $552(12)$ \\
\hline 0 times/month & $775(34)$ & $1,516(32)$ \\
\hline 1-7 times/month & $1,017(45)$ & 2,398 (51) \\
\hline $8 \geq$ times/month & $91(4)$ & $240(5)$ \\
\hline \multicolumn{3}{|l|}{ BMI (\%) } \\
\hline Underweight & $19(1)$ & $23(1)$ \\
\hline Normal & $279(30)$ & $1,593(32)$ \\
\hline Overweight & $1,034(43)$ & $2,262(46)$ \\
\hline Obesity & $634(26)$ & $1,040(21)$ \\
\hline \multicolumn{3}{|l|}{ Smoking status, (\%) } \\
\hline Never smoked & $749(31)$ & $1,759(36)$ \\
\hline Former smoker & $637(27)$ & $1,612(33)$ \\
\hline Current smoker & $1,004(42)$ & $1,517(31)$ \\
\hline \multicolumn{3}{|l|}{ Exercise, moderate (\%) } \\
\hline No exercise & $1,378(66)$ & $2,974(65)$ \\
\hline Moderate exercise & $699(34)$ & $1,575(35)$ \\
\hline \multicolumn{3}{|l|}{ Education in years (\%) } \\
\hline Primary school (\%) & $1,251(55)$ & $2,129(45.6)$ \\
\hline High school & $796(35)$ & $1,946(40.7)$ \\
\hline College & $211(9)$ & $653(13.7)$ \\
\hline \multicolumn{3}{|l|}{ Marital status (\%) } \\
\hline Not married/cohabitant & $941(38)$ & $1,226(25)$ \\
\hline Married/cohabitant, & $1,509(62)$ & $3,690(75)$ \\
\hline
\end{tabular}

Table 3 Comparison of measures of non-participants ${ }^{a}$ in HUNT3 with CWP in HUNT2, and the baseline sample ${ }^{b}$ (Continued)

Chronic disease, (\%)
No $\quad 873(39)$
Yes $1,345(61)$

the distribution of the pain by constructing and calculating the pain's breadth. This study examined pain only by pain duration and pain location (i.e. CWP) but not by pain intensity or temporal features, and thus the study did not differentiate between intermittent, fluctuating or continuous pain, nor if the pain was disease related [45].

\section{Weaknesses}

Defining chronic pain only by duration and location, but not by pain intensity or severity may weaken the study's optimality. In epidemiologic studies of pain, which are often based on self-report questionnaires rather than clinical findings, the complex nature of chronic pain represents a major challenge for the study's validity. Another weakness is that the participation rate decreased in the last HUNT study, as it does in most longitudinal population-based cohort studies. The attrition was $15 \%$ and was most pronounced among males and younger adults. A non-participant study based upon the HUNT2 study revealed that being abroad and the lack of time for scoring were the main reasons for nonattendance for people aged 20-44 years [36]. Decreased participation rates might threaten the internal validity in population-based studies [46]. In this study, the nonparticipants were likely to be older and less educated, experience sleeping problem and a chronic disease, and smoke on a daily basis. In general, non-participation in HUNT3 was characterized by lifestyle factors regarding smoking and physical inactivity, along with higher prevalence of several chronic diseases [46], which is in line with our findings. However, the participation rate for age groups 60 - 80 years in HUNT 3 were $65 \%$ to $70 \%$ compared to the overall participation rate of $54 \%$. We also believe that having the option to indicate bilateral pain at baseline, might have affected the sample size and thus the outcome. Meeting the ACR criteria of CWP by having chronic pain in all three major body areas paired with the option to indicate pain in both sides, may have resulted in a lower prevalence of baseline CWP and may have indicated a more severe pain condition. However, the baseline in this study covers all responders with CWP, including those with bilateral pain. 


\section{Possible interpretations}

Although this rather large study indicates that CWP occurs frequently in the general population, the conditions within CWP do not necessarily appear as invariable or unchanging, and with time, the individuals could move through various categories of chronic pain syndrome [47]. In this study a few factors point to pain persistence. Several factors not included in the HUNT2 study might explain why $53 \%$ of the baseline CWP persisted at followup. Lacking the possibility to indicate pain intensity and bilateral pain, which might indicate a level the pain condition's severity, could be one factor. In addition, detailed information on social aspects might be of interest in this context. Likewise, more detailed information on medical treatment such as analgesics, which the HUNT2 survey roughly offered, or comorbid conditions, could be of interest for explaining pain persistence. Data on medication were, however, omitted due to incomplete responses.

Yet, a substantial number of subjects at baseline (47\%) changed from having CWP at baseline to not having CWP at follow-up. The fact that a large proportion of the general population actually does resolve from CWP is additional knowledge for pain research and treatment. This finding is in contrast with other studies showing that the overall prevalence of CWP is stable over time and that pain is likely to persist if accompanied by, for example somatic symptoms and older age [31,32]. Our results may partly derive from investigating the general population in an 11year longitudinal follow-up study. Another reason may be due to another important finding, namely that CWP prevalence decreased among those at 60 years and older. This means that participants in their $50 \mathrm{~s}$ at baseline would accordingly be in their 60 s at follow-up, thus entering an age group associated with decreasing CWP. According to the present study, aging was not associated with an increased likelihood of persistent CWP. Instead, aging appeared to be a protective factor against chronicity, despite the fact that some rheumatic diseases, for example, occur at older ages. Still, it make senses to assume that the high prevalence of CWP (17\%) in this study may be related to the age distribution and the mean age of the HUNT cohort and the baseline sample, and the fact that CWP mainly affects middle-aged and older females and males $[47,48]$. These findings could indicate that CWP among the older population is poorly understood and mainly studied as a key symptom in fibromyalgia [39,47-50]. Associations between aging and pain are multidimensional, and at old(er) ages the problem of pain is considered to be highly complex due to multiple comorbidities [51]. Although multimorbidity becomes more common with age, more than the half those with multi-morbidity and nearly two-thirds with physical-mental health comorbidity are younger than 65 [52]. Our study revealed that having other chronic diseases was the strongest predictor of CWP persistence. Sex differences in pain reporting have been ascribed to a range of factors: e.g. pain perception factors such as menstrual cycle variations in pain sensitivity in younger females [48], the greater likelihood for females to visit a physician and to report long-lasting pain, the lower pain threshold among females and their greater prevalence of having pain related to autoimmune disease [18]. Males and females at older ages also differ in many of these factors $[48,53]$. Likewise, age-related sex differences may be due to biological (e.g. gonadal hormones) and psychosocial factors (e.g. older people are more exposed to depression, life cycle changes, etc.), as well as multi-morbidity as a part of aging [51], which means a shift in attention from pain to other conditions. A previous study [47] reported that the prevalence of CWP peaks at midlife and then slowly decreases. Another study [32] found that the highest prevalence of CWP was among those of 59-74 years of age. In line with other studies, we found a female over-representation both in the baseline sample (2:1) and among the respondents with persistent CWP at follow-up (3:1). The most frequently stated ratio for chronic musculoskeletal pain and CWP in males and females is that females are about $1 \frac{1}{2}$ times more likely to experience both chronic musculoskeletal pain and CWP [49]. We found that only sleeping problems was associated with persistent pain in females, just as only former smoking was associated with persistent pain in males. Except from the sex ratio and in terms of prognostic factors, we did not find specific sex differences among those with CWP at baseline.

Depression and anxiety disorders are commonly reported co-morbid conditions in CWP [26,29,47,54-57]. These are usually based on cross-sectional and clinical samples rather than prospective community subjects. Clauw and Crofford [49] suggested that by examining CWP in population-based studies, the bias from using clinical patient samples would be removed and CWP would be much similar to other chronic pain syndromes. In our large population-based study, we hypothesized that symptoms of anxiety and/or depression would predict the persistence of CWP at the 11year follow-up. However, we found only weak associations between symptoms of anxiety and mixed anxiety and depression and persistent CWP. Because depressive symptoms overlap with somatic symptoms in chronic pain conditions, depressive disorders could be over-diagnosed in people with chronic pain [58]. Likewise, it is possible that we were unable to reach those with severe pain or that the respondent's pain could be perceived as mild despite the chronicity and breadth or underlying musculoskeletal disease. Although these conditions often cause severe pains, knowing the origin of the pain and/or having an opportunity to receive adequate treatment could influence how the subjects deal with suffering from a long-standing chronic pain condition. According to Dersh and colleagues [59], there are several reasons for considering chronic pain and mood disorders as distinct 
disorders even though the underlying patho-physiologies may share common factors. The onset of pain and mild psychological disturbances do not typically coincide, and each condition could be mutually independent for many individuals [59]. While those with chronic pain and psychological distress frequently tend to consult health services, not all those with chronic pain experience psychological distress as anxiety or depression [60], which might explain the weak associations in our study. Considering BMI, only obesity had a substantial effect on persistent CWP. According to several prospective studies, being overweight and obese are risk factors for chronic pain because weight gains increases bodily strains, especially strains in joints [61-63]. Our findings support a previous study reporting that CWP is significantly associated with obesity alone, but weakly associated with being overweight [63].

\section{Conclusion}

The results demonstrated that many respondents (53\%) in the general population maintained CWP, but a large proportion (47\%) also resolved within an 11-year period. Persistent CWP was examined in association with important cofactors suggested by previous research. The study revealed strong positive associations over time with sleeping problems, obesity and chronic disease, while being 60 years or older was protective. Contrary to other studies, depression, anxiety and the frequency of alcohol consumption were not substantial predictors of outcome. Except from the sex differences in prevalence, the adjusted analyses revealed no prominent sex differences related to the predictors or protectors of CWP persistence. This large prospective population-based study brings new knowledge about what is important for longterm CWP persistence. Additional prospective population studies could reveal predictive factors for why many CWP individuals recover and why others do not recover from pain.

\section{Competing interests}

The authors declare no conflict of interest.

\section{Authors' contributions}

IM was responsible for collecting and analysing data and manuscript drafting. RWG, OML and EAF contributed to the study's conception, as well critical revision and manuscript drafting. JHB was involved in the data analysis and statistical interpretation, and contributed in particular with methodical and epidemiological support and critical revision and manuscript revising and drafting. All authors have made substantial intellectual contributions and read and approved the final manuscript.

\section{Acknowledgements}

The Nord-Trøndelag Health Study (The HUNT Study) is the collaboration between HUNT Research Centre (Faculty of Medicine, Norwegian University of Science and Technology NTNU), Nord-Trøndelag County Council, Central Norway Health Authority, and the Norwegian Institute of Public Health.

\section{Author details}

'Department of Neuroscience, Faculty of Medicine, Norwegian University of Science and Technology, 7491 Trondheim, Norway. ${ }^{2}$ Outpatient Department of Psychiatry, Kristiansund Hospital, Møre and Romsdal Hospital Trust, Kristiansund, Norway. ${ }^{3}$ Department of Research and Development, Addiction
Medicine, St. Olav's University Hospital, Trondheim, Norway. ${ }^{4}$ Department of Public Health and General Practice, Faculty of Medicine, Norwegian University of Science and Technology, Trondheim, Norway. ${ }^{5}$ Forensic Department and Research Centre Bröset, St Olav's University Hospital, Trondheim, Norway. ${ }^{6}$ Department of Psychiatry, Department of Research and Development, St Olavs University Hospital, Trondheim, Norway. ${ }^{7}$ Department of Psychiatry, St Olavs University Hospital, Trondheim, Norway.

Received: 22 August 2013 Accepted: 10 June 2014

Published: 20 June 2014

\section{References}

1. Croft P, Blyth FM, van der Windt D: The global occurence of chronic pain. An introduction. Chronic Pain Epidemiology. From Aetiology to Public Health. New York: Oxford University Press; 2010:9-18.

2. Neville A, Peleg R, Singer Y, Sherf M, Shvartzman P: Chronic pain: a population-based study. Isr Med Assoc J 2008, 10(10):676-680.

3. Portenoy RK, Ugarte C, Fuller I, Haas G: Population-based survey of pain in the United States: differences among white, African American, and Hispanic subjects. J Pain 2004, 5(6):317-328.

4. Tsang A, Von Korff M, Lee S, Alonso J, Karam E, Angermeyer MC, Borges GL, Bromet EJ, Demytteneare K, de Girolamo G, de Graaf R, Gureje O, Lepine JP, Haro JM, Levinson D, Oakley Browne MA, Posada-Villa J, Seedat S, Watanabe M: Common chronic pain conditions in developed and developing countries: gender and age differences and comorbidity with depressionanxiety disorders. J Pain 2008, 9(10):883-891.

5. Breivik H, Collett B, Ventafridda V, Cohen R, Gallacher D: Survey of chronic pain in Europe: prevalence, impact on daily life, and treatment. Eur J Pain 2006, 10(4):287-333

6. Vellucci R: Heterogeneity of chronic pain. Clin Drug Investig 2012, 32(Suppl 1):3-10.

7. Hjermstad MJ, Fayers PM, Haugen DF, Caraceni A, Hanks GW, Loge JH, Fainsinger R, Aass N, Kaasa S, European Palliative Care Research C: Studies comparing numerical rating scales, verbal rating scales, and visual analogue scales for assessment of pain intensity in adults: a systematic literature review. J Pain Symptom Manage 2011, 41(6):1073-1093.

8. Jensen MP, McFarland CA: Increasing the reliability and validity of pain intensity measurement in chronic pain patients. Pain 1993, 55(2):195-203.

9. Jensen MP, Dworkin RH, Gammaitoni AR, Olaleye DO, Oleka N, Galer BS: Do pain qualities and spatial characteristics make independent contributions to interference with physical and emotional functioning? J Pain 2006, 7(9):644-653.

10. Andersson $\mathrm{HI}$ : The course of non-malignant chronic pain: a 12-year follow-up of a cohort from the general population. Eur J Pain 2004, 8(1):47-53.

11. Carnes D, Parsons S, Ashby D, Breen A, Foster NE, Pincus T, Vogel S, Underwood M: Chronic musculoskeletal pain rarely presents in a single body site: results from a UK population study. Rheumatology (Oxford) 2007, 46(7):1168-1170.

12. Kamaleri $Y$, Natvig B, Ihlebaek CM, Benth JS, Bruusgaard D: Change in the number of musculoskeletal pain sites: A 14-year prospective study. Pain 2009, 141(1-2):25-30.

13. Blyth FM: Chronic pain-is it a public health problem? Pain 2008 , 137(3):465-466.

14. Lindell L, Bergman S, Petersson IF, Jacobsson LT, Herrstrom P: Prevalence of fibromyalgia and chronic widespread pain. Scand J Prim Health Care 2000, 18(3):149-153

15. McBeth J, Nicholl BI, Cordingley L, Davies KA, Macfarlane GJ: Chronic widespread pain predicts physical inactivity: results from the prospective EPIFUND study. Eur J Pain 2010, 14(9):972-979.

16. Wolfe F, Smythe HA, Yunus MB, Bennett RM, Bombardier C, Goldenberg DL, Tugwell P, Campbell SM, Abeles M, Clark P, Fam AG, Farber S, Fiechtner JJ, Franklin CM, Gatfer RA, Hamaty D, Lessard J, Lichtbroun AS, Masi AT, Mccain GA, Reynolds WJ, Romano TJ, Russell IJ, Sheon RP: The American college of rheumatology 1990 criteria for the classification of fibromyalgia. Report of the multicenter criteria committee. Arthritis Rheum 1990, 33(2):160-172.

17. Greenspan JD, Craft RM, LeResche L, Arendt-Nielsen L, Berkley KJ, Fillingim RB, Gold MS, Holdcroft A, Lautenbacher S, Mayer EA, Mogil JS, Murphy AZ, Traub RJ: Studying sex and gender differences in pain and analgesia: a consensus report. Pain 2007, 132(Suppl 1):S26-S45. 
18. Hurley RW, Adams MC: Sex, gender, and pain: an overview of a complex field. Anesth Analg 2008, 107(1):309-317.

19. Thomas E, Peat G, Harris L, Wilkie R, Croft PR: The prevalence of pain and pain interference in a general population of older adults: cross-sectional findings from the North Staffordshire Osteoarthritis Project (NorStOP) Pain 2004, 110(1-2):361-368.

20. Ohayon MM, Schatzberg AF: Using chronic pain to predict depressive morbidity in the general population. Arch Gen Psychiatry 2003, 60(1):39-47

21. Hagen K, Linde M, Heuch I, Stovner LJ, Zwart JA: Increasing prevalence of chronic musculoskeletal complaints. A large 11-year follow-up in the general population (HUNT 2 and 3). Pain Med 2011, 12(11):1657-1666.

22. Smith BH, Macfarlane GJ, Torrance N: Epidemiology of chronic pain, from the laboratory to the bus stop: time to add understanding of biological mechanisms to the study of risk factors in population-based research? Pain 2007, 127(1-2):5-10.

23. Hitt HC, McMillen RC, Thornton-Neaves T, Koch K, Cosby AG: Comorbidity of obesity and pain in a general population: results from the Southern Pain Prevalence Study. J Pain 2007, 8(5):430-436.

24. Vandenkerkhof EG, Macdonald HM, Jones GT, Power C, Macfarlane GJ: Diet, lifestyle and chronic widespread pain: results from the 1958 British birth cohort study. Pain Res Manag 2011, 16(2):87-92.

25. Gureje O, Von Korff M, Kola L, Demyttenaere K, He Y, Posada-Villa J, Lepine JP, Angermeyer MC, Levinson D, de Girolamo G, Iwata N, Karam A, Guimaraes Borges GL, de Graaf R, Browne MO, Stein DJ, Haro JM, Bromet EJ, Kessler RC, Alonso J: The relation between multiple pains and mental disorders: results from the World Mental Health Surveys. Pain 2008, 135(1-2):82-91.

26. Gupta A, Silman AJ, Ray D, Morriss R, Dickens C, MacFarlane GJ, Chiu YH, Nicholl B, McBeth J: The role of psychosocial factors in predicting the onset of chronic widespread pain: results from a prospective populationbased study. Rheumatology (Oxford) 2007, 46(4):666-671.

27. Nicholl BI, Macfarlane GJ, Davies KA, Morriss R, Dickens C, McBeth J: Premorbid psychosocial factors are associated with poor health-related quality of life in subjects with new onset of chronic widespread pain results from the EPIFUND study. Pain 2009, 141(1-2):119-126.

28. Davies KA, Macfarlane GJ, Nicholl BI, Dickens C, Morriss R, Ray D, McBeth J: Restorative sleep predicts the resolution of chronic widespread pain: results from the EPIFUND study. Rheumatology (Oxford) 2008, 47(12):1809-1813.

29. Larsson B, Bjork J, Borsbo B, Gerdle B: A systematic review of risk factors associated with transitioning from regional musculoskeletal pain to chronic widespread pain. Eur J Pain 2012, 16(8):1084-1093.

30. MacFarlane GJ, Thomas E, Papageorgiou AC, Schollum J, Croft PR, Silman AJ: The natural history of chronic pain in the community: a better prognosis than in the clinic? J Rheumatol 1996, 23(9):1617-1620.

31. Papageorgiou AC, Silman AJ, Macfarlane GJ: Chronic widespread pain in the population: a seven year follow up study. Ann Rheum Dis 2002, 61(12):1071-1074.

32. Bergman S, Herrstrom P, Jacobsson LT, Petersson IF: Chronic widespread pain: a three year followup of pain distribution and risk factors. J Rheumatol 2002, 29(4):818-825.

33. Forseth $\mathrm{KO}$, Forre $\mathrm{O}$, Gran JT: A 5.5 year prospective study of self-reported musculoskeletal pain and of fibromyalgia in a female population: significance and natural history. Clin Rheumatol 1999, 18(2):114-121.

34. Campbell LC, Clauw DJ, Keefe FJ: Persistent pain and depression: a biopsychosocial perspective. Biol Psychiatry 2003, 54(3):399-409.

35. Holmen J, Midthjell $K$, Krüger $O$, Langhammer A, Holmen TL, Bratberg GH, Vatten L, Lund-Larsen PG: The Nord-Trøndelag Health Study 1995-97 (HUNT 2): Objectives, contents, methods and participation. Norsk Epidemiologi 2003, 13(1):19-33.

36. Krokstad S, Langhammer A, Hveem K, Holmen T, Midthjell K, Stene T, Bratberg G, Heggland J, Holmen J: Cohort profile: the HUNT study, Norway. Int J Epidemiol 2012, 42(4):968-977

37. Kuorinka I, Jonsson B, Kilbom A, Vinterberg H, Biering-Sorensen F, Andersson $\mathrm{G}$, Jorgensen K: Standardised Nordic questionnaires for the analysis of musculoskeletal symptoms. Appl Ergon 1987, 18(3):233-237.

38. Aggarwal VR, McBeth J, Zakrzewska JM, Lunt M, Macfarlane GJ: The epidemiology of chronic syndromes that are frequently unexplained: do they have common associated factors? Int J Epidemio/ 2006, 35(2):468-476.

39. Wolfe F, Clauw DJ, Fitzcharles MA, Goldenberg DL, Katz RS, Mease P, Russell AS, Russell IJ, Winfield JB, Yunus MB: The American college of rheumatology preliminary diagnostic criteria for fibromyalgia and measurement of symptom severity. Arthritis Care Res (Hoboken) 2010 62(5):600-610

40. Bjelland I, Dahl AA, Haug T, Neckelmann D: The validity of the hospital anxiety and depression scale. An updated literature review. J Psychosom Res 2002, 52(2):69-77.

41. Mykletun A, Stordal E, Dahl AA: Hospital Anxiety and Depression (HAD) scale: factor structure, item analyses and internal consistency in a large population. Br J Psychiatry 2001, 179:540-544.

42. Stordal E, Bjelland I, Dahl AA, Mykletun A: Anxiety and depression in individuals with somatic health problems. The Nord-Trondelag Health Study (HUNT). Scand J Prim Health Care 2003, 21(3):136-141.

43. Riskind JH, Beck AT, Berchick RJ, Brown G, Steer RA: Reliability of DSM-III diagnoses for major depression and generalized anxiety disorder using the structured clinical interview for DSM-III. Arch Gen Psychiatry 1987, 44(9):817-820.

44. World Health Organization: Obesity: preventing and managing the global epidemic. Report of a WHO consultation. World Health Organ Tech Rep Ser 2000, 894:i-xii. 1-253.

45. Wong WS, Fielding R: Prevalence and characteristics of chronic pain in the general population of Hong Kong. J Pain 2011, 12(2):236-245

46. Langhammer A, Krokstad S, Romundstad P, Heggland J, Holmen J: The HUNT study: participation is associated with survival and depends on socioeconomic status, diseases and symptoms. BMC Med Res Methodol 2012, 12:143.

47. Gran JT: The epidemiology of chronic generalized musculoskeletal pain. Best Pract Res Clin Rheumatol 2003, 17(4):547-561.

48. Leveille SG, Zhang Y, McMullen W, Kelly-Hayes M, Felson DT: Sex differences in musculoskeletal pain in older adults. Pain 2005, 116(3):332-338.

49. Clauw DJ, Crofford LJ: Chronic widespread pain and fibromyalgia: what we know, and what we need to know. Best Pract Res Clin Rheumatol 2003, 17(4):685-701.

50. DeSantana JM, Sluka KA: Central mechanisms in the maintenance of chronic widespread noninflammatory muscle pain. Curr Pain Headache Rep 2008, 12(5):338-343.

51. Barnett K, Mercer SW, Norbury M, Watt G, Wyke S, Guthrie B: Epidemiology of multimorbidity and implications for health care, research, and medical education: a cross-sectional study. Lancet 2012, 380(9836):37-43.

52. Taylor AW, Price K, Gill TK, Adams R, Pilkington R, Carrangis N, Shi Z, Wilson $D$ : Multimorbidity - not just an older person's issue. Results from an Australian biomedical study. BMC public health 2010, 10:718.

53. Gagliese L: Pain and aging: the emergence of a new subfield of pain research. J Pain 2009, 10(4):343-353.

54. Bair MJ, Robinson RL, Katon W, Kroenke K: Depression and pain comorbidity: a literature review. Arch Intern Med 2003, 163(20):2433-2445.

55. Macfarlane GJ, McBeth J, Silman AJ: Widespread body pain and mortality: prospective population based study. BMJ 2001, 323(7314):662-665

56. Macfarlane GJ, Morris S, Hunt IM, Benjamin S, McBeth J, Papageorgiou AC, Silman AJ: Chronic widespread pain in the community: the influence of psychological symptoms and mental disorder on healthcare seeking behavior. J Rheumatol 1999, 26(2):413-419.

57. McBeth J, Macfarlane GJ, Hunt IM, Silman AJ: Risk factors for persistent chronic widespread pain: a community-based study. Rheumatology (Oxford) 2001, 40(1):95-101.

58. Benjamin S, Morris S, McBeth J, Macfarlane GJ, Silman AJ: The association between chronic widespread pain and mental disorder: a populationbased study. Arthritis Rheum 2000, 43(3):561-567.

59. Dersh J, Polatin PB, Gatchel RJ: Chronic pain and psychopathology: research findings and theoretical considerations. Psychosom Med 2002, 64(5):773-786.

60. McBeth J, Macfarlane GJ, Silman AJ: Does chronic pain predict future psychological distress? Pain 2002, 96(3):239-245

61. Janke EA, Collins A, Kozak AT: Overview of the relationship between pain and obesity: What do we know? Where do we go next? I Rehabil Res Dev 2007, 44(2):245-262. 
62. Tukker A, Visscher TL, Picavet HS: Overweight and health problems of the lower extremities: osteoarthritis, pain and disability. Public Health Nutr 2009, 12(3):359-368.

63. Wright LJ, Schur E, Noonan C, Ahumada S, Buchwald D, Afari N: Chronic pain, overweight, and obesity: findings from a community-based twin registry. J Pain 2010, 11(7):628-635.

doi:10.1186/1471-2474-15-213

Cite this article as: Mundal et al:: Prevalence and long-term predictors of persistent chronic widespread pain in the general population in an 11-year prospective study: the HUNT study. BMC Musculoskeletal Disorders 2014 15:213.

\section{Submit your next manuscript to BioMed Central and take full advantage of:}

- Convenient online submission

- Thorough peer review

- No space constraints or color figure charges

- Immediate publication on acceptance

- Inclusion in PubMed, CAS, Scopus and Google Scholar

- Research which is freely available for redistribution 